\title{
ANALYSIS OF LATERAL DISPLACEMENT AND EVALUATION OF TREATMENT MEASURES OF CURVED BEAM: A CASE STUDY
}

\author{
Jie Li, Dongchao Liang, Junfeng Zhang, Zhaodong Shi and Huai Chen \\ School of Civil Engineering, Zhengzhou University, 100, Science Avenue \\ Zhengzhou, Henan China 450001; lijie2007@zzu.edu.cn,2428175429@qq.com, \\ brilliantshine@163.com,1256304513@qq.com,chenh@zzu.edu.cn
}

\begin{abstract}
The curved beam bridge exhibits lateral displacement during construction and operation. Taking a curved beam bridge as an example, the status of lateral displacement of the bridge is investigated in detail in this paper. To understand the mechanism of the curved beam lateral displacement, further to determine the curved beam lateral displacement under temperature effect, using ANSYS software to establish solid element model of the curved beam, steady state thermal analysis method is applied to analyze temperature field. Based on the analysis, the lateral displacement under temperature effect is analyzed. Then in order to further explain the lateral displacement mechanism, to discuss the frictional force causing the residual deformation of the rubber bearing to make the lateral displacement of the curved beam, the mechanical mechanism of curved beam under temperature effect is approximately analyzed. On the basis of clarifying the mechanism of lateral displacement, the paper puts forward the reinforcement measures for the curved beam bridge. In order to verify the treatment effect, long-term displacement monitoring is performed on the bridge. Numerical studies and monitoring data show that temperature is the main factor that causes the lateral displacement. Monitoring data over the past year shows that the displacement of the bearing is less than the value of allowable displacement after the reinforcement measures are adopted, and the bridge is in a safe state.
\end{abstract}

\section{KEYWORDS}

Curved beam bridge, Lateral displacement, Numerical analysis, Reinforcement and renovation, Long-term monitoring

\section{INTRODUCTION}

Curved beam bridge is a typical "bending-torsional coupling" stress member. The mechanical characteristics of curved beam bridge is unique due to its curvature. It is different from straight beam bridge in terms of stress and deformation. The most significant difference is the lateral displacement of curved beam bridge. At present, most of the researches on the lateral displacement of curved beam bridges are mainly based on the finite element method [1-5]. A few studies on external affecting factors of displacement have analyzed dead weight, live load, and prestressed load [6]. Some studies suggest that temperature [7-8] and live load are the main reasons of beam bridge disease. The study of temperature has mainly focused on the temperature distribution of bridges [9] and the mechanism of the influence of temperature on lateral displacement [10]. In terms of measures to cope with the lateral displacement of bridges, several scholars have given reinforcement [11] and reconstruction measures for bridges with transverse displacement diseases [12] for effectively controlling the development of bridge diseases. 
The above-mentioned works show that the curved beam bridge will inevitably have lateral displacement, which may lead to lateral deviation disease. The main affecting factors of lateral deviation include radius of curvature, temperature, and vehicle load and so on. At present, most studies only conduct elastic analysis of transverse displacement under the action of various factors while ignoring the essence of lateral deviation disease. However, during operation of curved beam bridge, lateral displacement occurs under the combined action of internal and external factors. The lateral displacement generated by the beam cannot be fully recovered, after the external force disappears due to the friction between the bearing and bottom of the beam and the action of its own gravity. Residual lateral displacement occurs every time when the external force acts. The lateral displacement keeps accumulating through the cycle action of the external load, and the energy inside the curved beam also accumulates. When the internal energy of the beam reaches its peak, the beam starts to release energy under the action of accidental external force. This condition may lead to the crack of the beam, the tensile crack of the expansion joint, or the outward slide of the beam. During operation of curved beam bridge, lateral displacement diseases, which are mainly manifested as transverse deflection and torsional displacement of beam, occur. Therefore, the mechanism of lateral deflection disease of curved beam bridge requires further investigation. In this study, taking a curved beam bridge as an example, on the basis of the detailed investigation of the lateral displacement disease, the numerical method is used to analyze the causes of the lateral displacement, and the reinforcement measures are proposed. Finally, the operation status of the bridge is evaluated by the measured data of a long-term health monitoring.

\section{PROJECT OVERVIEW AND DISEASE STATUS INVESTIGATION}

\section{Brief introduction of engineering example}

The engineering example is a ramp curved beam bridge. Total length of the curved beam is $1202.7 \mathrm{~m}$, with 12 parts, 43 spans and 42 piers. The width of the bridge is $9.5 \mathrm{~m}$, with two lanes. Limited to space, the third part of the curved beam is taken as the engineering object. The third part of the curved beam is located on the curve $R=400 \mathrm{~m}$ and the layout of the bridge span is ( $40+$ $51.5+40) \mathrm{m}$. PC continuous box beam with inclined webs is used in the superstructure. The section of main beam is single box and single chamber (See Figure 1, the black spot represents the temperature measuring point.). The corbel is used to overlap the units and expansion joints are set at the corbel.

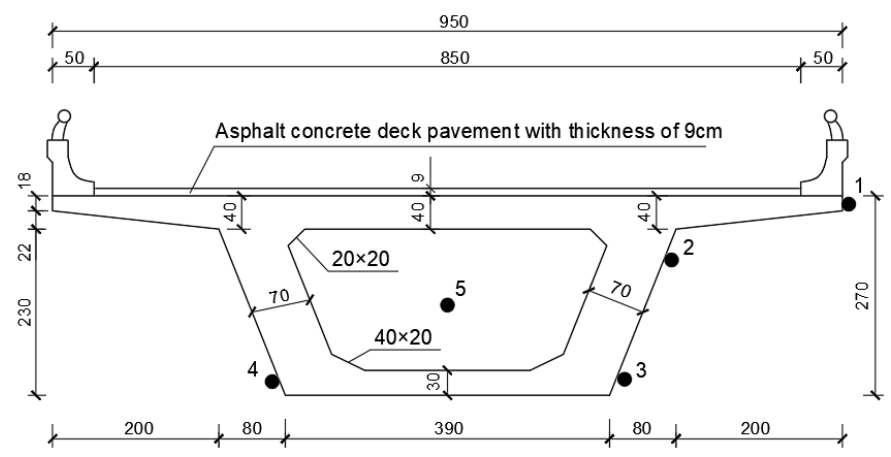

(a)

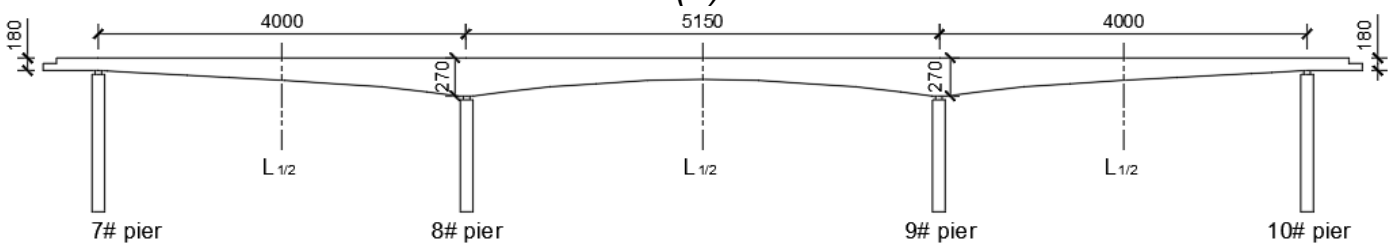

(b)

Fig. 1 - The third parts of the curved beam (cm) 
The cantilever length of flange is $2.0 \mathrm{~m}$. The beam height at the pier is $2.7 \mathrm{~m}$ and the mid span beam height is $1.8 \mathrm{~m}$. The thickness of the top plate changes from $0.4 \mathrm{~m}$ at the pier to $0.25 \mathrm{~m}$ in the mid-span. The thickness of the bottom plate gradually changes from $0.3 \mathrm{~m}$ at the pier to 0.22 $\mathrm{m}$ in the mid-span. The thickness of web is $0.5-0.7 \mathrm{~m}$. Longitudinal prestressed reinforcement is steel strand with high strength and low relaxation yield strength of $1860 \mathrm{MPa}$, which is designed according to class A partial prestressed concrete. Rectangular single column pier is used in the substructure, and the pier top is widened horizontally to place pot type rubber double bearing. The bearing forms include one- direction bearing, two- direction bearing and fixed bearing. The transverse widening of pier column from pier top to pier body adopts straight line transition. The pier body size is $1.4 \times 2.0 \mathrm{~m}$. The bearing spacing of No.8 and No.9 piers is $2.0 \mathrm{~m}$, and that of No.7 and No.10 side piers is $1.8 \mathrm{~m}$. C50 concrete is used for main beam and C40 concrete is used for pier.

\section{Disease status investigation}

Under the influence of external loads such as temperature, concrete shrinkage and creep, as well as live load, the curved beam bridge has serious lateral displacement disease, which has led to beam cracks, bearing lateral displacement and damage.

\section{Cracks in main beam}

According to the field investigation, there are vertical cracks in the outer web of the main beam structure, transverse cracks in the wing plate, and oblique cracks in the outer web of the corbel connection. In the whole bridge, the width of the two inclined cracks which is away from the No.40 pier $4.5 \mathrm{~m}$ is $0.15 \mathrm{~mm}$, and the other cracks are about $0.1 \mathrm{~mm}$. The theoretical calculation shows that [9], because the crossbeams of the curved beam bridge are all solid sections, and there are more common reinforcing bars, the crack resistance capacity of the beam can meet the structural stress requirements. The analysis also shows that the web cracks of beam body are mainly caused by concrete shrinkage and creep, but some web cracks of beam span are caused by transverse force of beam that produced by lateral displacement. Figure 2 shows a diagonal crack on the outer web of the 23 rd corbel connection.

\section{Lateral displacement deviation of curved beam}

The transverse slip of the main beam and the support is concentrated in the span with small curvature radius, and no obvious disease is found in other parts. The maximum slip of the main beam bearing to the outside of the curve is $40 \mathrm{~cm}$ (shown in Figure 3). The numerical analysis [9] shows that the lateral displacement of the beam is mainly caused by the temperature effect, especially the transverse temperature gradient. Other factors, such as the concrete shrinkage and creep effect, the insufficient lateral limit, the large longitudinal slope of the bridge, and the lack of the limiting device for each pier of the bridge, will further worsen the disease.

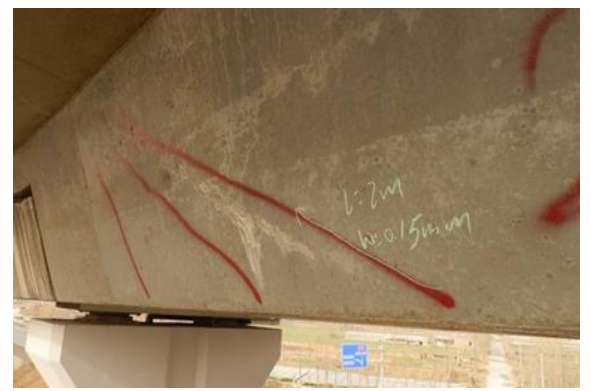

Fig. 2 - Diagonal cracks in web

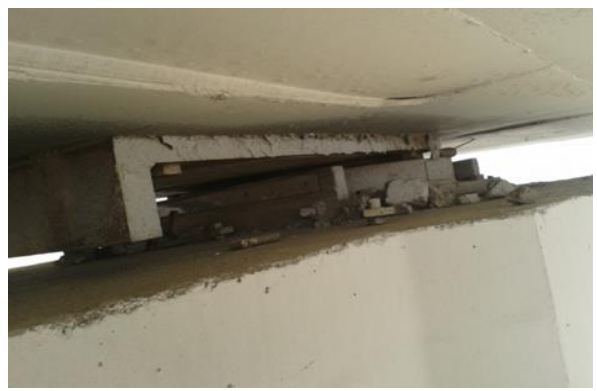

Fig. 3 - Lateral slip $40 \mathrm{~cm}$ 
In the bridge span with large lateral displacement, the main problems of bearing are that the anchor bolt is sheared off, the limit steel plate is sheared off, the rubber body is ejected, and the beam concrete is damaged. The bearing damage is shown in Figure 4.

\section{Bridge pier diseases}

Due to the lateral displacement, the stress of the pier is unfavourable, which leads to cracks of the pier. The field investigation is shown in Figure 5. In addition, damages to the bridge deck and ancillary structures were also found on site, such as rubber strip breaking and mud inclusion in the expansion device, widening of some expansion joint gaps and lateral dislocation, and vertical cracks at the guardrail.

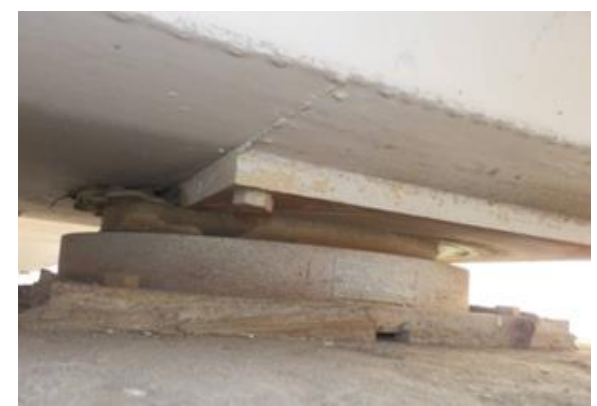

Fig. 4 - Bearing damage

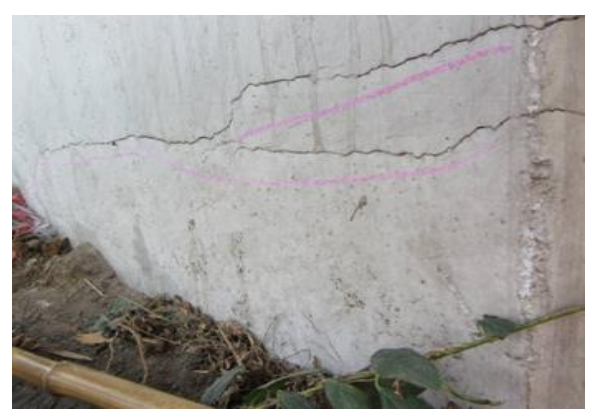

Fig. 5- Bridge pier cracks

\section{LATERAL DISPLACEMENT MECHANISM OF CURVED BEAM BRIDGE UNDER TEMPERATURE EFFECT}

A large number of studies show that temperature is the main cause of lateral displacement of curved beam bridge [9, 11]. Therefore, in view of the engineering example, the lateral displacement mechanism of curved beam bridge is discussed under the temperature effect.

\section{Finite element modelling and temperature gradient field simulation}

The finite element model of the third parts of the curved beam bridge is established by using ANSYS finite element software. The model mainly analyzes the response of the structure under the action of primary load (temperature effect) instead of long-term repeated load. In order to further simulate the physical process of residual displacement accumulation caused by bearing friction resistance, the accumulation process of residual displacement of bearing under repeated load is simulated by using combine39 element in ANSYS software.

The effect of temperature on curved beam bridge can be divided into two categories: (1) temperature gradient: including vertical temperature gradient and radial temperature gradient; (2) system temperature difference. According to the field measurement, the maximum temperature difference between the top and bottom plates of the box beam section of the bridge is about $10^{\circ} \mathrm{C}$, and the vertical linear temperature difference is $10^{\circ} \mathrm{C}$ according to General Specification for Design of Highway Bridges and Culverts (JTG D60-2015). The transverse temperature gradient of box beam section is given in reference [9]. The trend of the bridge analyzed in this paper is from north to southeast. According to the field measurement of some bridges, the temperature difference between the inner and outer webs of the main beam can be as high as $10^{\circ} \mathrm{C}$, so the transverse temperature gradient is taken as $10^{\circ} \mathrm{C}$. This paper mainly analyzes the influence of three temperature gradient conditions on the displacement of curved beam bridge. 
$\mathrm{CS} 1$ : the inner temperature is $20^{\circ} \mathrm{C}$ and the outer temperature is $30^{\circ} \mathrm{C}$;

CS2: the inner temperature is $30^{\circ} \mathrm{C}$ and the outer temperature is $20^{\circ} \mathrm{C}$;

CS3: the temperature of top plate is $10^{\circ} \mathrm{C}$.

When analyzing the influence of system temperature difference on the displacement of curved beam bridge, according to the environment of the bridge site and relevant temperature data and relevant literature, the system temperature difference of $30^{\circ} \mathrm{C}$ is taken, and the displacement of curved beam bridge with system temperature difference of $20^{\circ} \mathrm{C}$ and $40^{\circ} \mathrm{C}$ is compared.

\section{Analysis without considering friction and long-term cumulative effect of bearing}

According to the analysis mode of one-time load instead of long-term repeated load, the transverse displacement of main beam replaces long-term lateral cumulative displacement. That is, the temperature load is applied to the curved beam according to the temperature field distribution. The bearing reaction force and beam displacement are analysed without considering the hyperelastic material and its friction, and the long-term cumulative effect. The number and section position are shown in Figure 1.

(1) Thermal analysis: input thermal element and heat conduction coefficient during thermal analysis. The solid element model is established. Then, the temperature boundary conditions are defined, and the steady-state thermal analysis is carried out. The temperature field of each node is calculated.

(2) Structural analysis: after entering the stage of structural analysis, the thermal element is transformed into structural element, and various parameters and reference temperature of main beam are input. The temperature of each node obtained from the thermal analysis is applied to the main beam structure for mechanical analysis.

Table 1 and Table 2 show the reaction force of support and radial displacement of beam under different temperature gradient conditions.

Tab. 1 - Reaction force of curved beam under temperature gradient ( $k N$ )

\begin{tabular}{|c|c|c|c|c|c|c|}
\hline \multirow[b]{2}{*}{ Bearing position } & \multicolumn{2}{|c|}{ CS1 } & \multicolumn{2}{|c|}{ CS2 } & \multicolumn{2}{|c|}{ CS3 } \\
\hline & $\begin{array}{l}\text { Transverse } \\
\text { direction of } \\
\text { bridge (FX } \\
\text { ) }\end{array}$ & $\begin{array}{l}\text { Vertical } \\
\text { direction of } \\
\text { bridge (FY }\end{array}$ & $\begin{array}{l}\text { Transverse } \\
\text { direction of } \\
\text { bridge (FX } \\
\text { ) }\end{array}$ & $\begin{array}{c}\text { Vertical } \\
\text { direction of } \\
\text { bridge (FY } \\
\text { ) }\end{array}$ & $\begin{array}{l}\text { Transverse } \\
\text { direction of } \\
\text { bridge (FX } \\
\text { ) }\end{array}$ & $\begin{array}{l}\text { Vertical } \\
\text { direction of } \\
\text { bridge } \\
(F Y)\end{array}$ \\
\hline Pier 7\# outside & 10.11 & 457.20 & 16.14 & -544.90 & 2.78 & 39.79 \\
\hline Pier 7\# inside & -273.55 & -440.67 & 284.07 & 548.78 & 20.52 & 63.97 \\
\hline Pier 8\# outside & 584.01 & -302.35 & -588.67 & 226.37 & 1.46 & -59.20 \\
\hline Pier 8\# inside & -274.15 & 288.53 & 338.32 & -225.33 & 33.92 & -39.35 \\
\hline Pier $9 \#$ outside & 21.85 & -276.86 & 12.77 & 209.53 & 1.42 & -69.63 \\
\hline Pier 9\# inside & 271.88 & 257.61 & -257.02 & -211.55 & 33.50 & -39.18 \\
\hline Pier 10\# outside & 9.53 & 426.41 & 19.44 & -473.12 & 3.96 & 30.78 \\
\hline Pier $10 \#$ inside & -267.04 & -409.88 & 271.92 & 470.25 & 18.78 & 72.82 \\
\hline
\end{tabular}


Tab. 2 - Radial displacement of curved beam under temperature gradient ( $\mathrm{mm}$ )

\begin{tabular}{ccccc}
\hline & Position & \multicolumn{3}{c}{ Radial displacement } \\
& CS1 & CS2 & CS3 \\
\hline \multirow{3}{*}{ Pier 7\# } & Bottom of main beam & 1.01 & -1.31 & -0.16 \\
& Pier top & 1.04 & -1.27 & -0.15 \\
& Relative displacement & -0.03 & -0.04 & -0.01 \\
\hline & L/2 & -0.66 & 0.52 & -0.10 \\
\hline \multirow{3}{*}{ Pier 8\# } & Bottom of main beam & -0.76 & 0.69 & -0.09 \\
& Pier top & -0.76 & 0.69 & -0.09 \\
& Relative displacement & 0.0 & 0.0 & 0.0 \\
\hline & L/2 & -0.52 & 0.34 & -0.18 \\
\hline \multirow{3}{*}{ Pier 9\# } & Bottom of main beam & -0.80 & 0.62 & -0.10 \\
& Pier top & -0.75 & 0.65 & -0.10 \\
& Relative displacement & -0.05 & -0.03 & 0 \\
\hline \multirow{2}{*}{ Pier 10\# } & L/2 $\quad-0.64$ & 0.45 & -0.1 \\
& Bottom of main beam & 1.18 & -1.41 & -0.16 \\
& Pier top & 1.21 & -1.36 & -0.15 \\
& Relative displacement & -0.03 & -0.05 & -0.01 \\
\hline
\end{tabular}

It can be seen from Table 1 that under the action of temperature, the vertical bearing reaction force of curved beam bridge are relatively large. The sign of the reaction force of the inner and outer vertical supports on each pier is opposite. Under CS1 condition, the vertical bearing reaction of the inner supports at both ends of the main beam and the outer support of the middle pier is negative. The lateral torsion occurs at both ends of the beam, and the inner torsion occurs at other positions. It is the opposite under CS2. Due to the difference of arc length between inside and outside of curved beam bridge, the expansion and elongation of inner and outer arc length are not consistent under the action of temperature, which leads to radial displacement of beam. The lateral offset of curved beam bridge is restrained by the support, and the radial bearing reaction force is produced. Compared with CS1 and CS2, the transverse direction support reaction of CS3 is smaller. Under the action of vertical temperature gradient, the top plate of box beam is heated up and it is arched upward, which mainly causes the vertical deflection of the beam. Under the action of CS3, 7\# and 10\# bearings at both ends are compressed, and the absolute value of reaction force of inner bearing is greater than that of outer bearing. 8\# and 9\# internal and external supports are under tension, and the vertical reaction force of outer bearing is greater than that of inner bearing.

It can be seen from Table 2 that under CS1, both ends of the beam deviate to the inside and the middle to the outside. The maximum internal offset is $1.18 \mathrm{~mm}$ and the maximum lateral offset is $0.8 \mathrm{~mm}$. Under CS2, the lateral offset occurs at both ends of the beam, and the inner offset occurs in the middle. The maximum lateral offset is $1.41 \mathrm{~mm}$ and the maximum inner offset is $0.65 \mathrm{~mm}$. Compared with CS1 and CS2, under CS3, the curved beam bridge moves outward, and the maximum offset is $0.16 \mathrm{~mm}$.

The displacement of main beam under the action of system temperature difference is shown in Table 3, Figure 4 and Figure 5. In Table 3, the radial displacements selected at the bottom of main beam, pier top and mid-span of each span are absolute displacement, and relative displacement is the radial displacement of main beam relative to pier top. 
Article no. 9

THE CIVIL ENGINEERING JOURNAL 1-2021

ENGINEERING

JOURNAL

Tab. 3 - Radial displacement of curved beam under the action of system temperature difference

\begin{tabular}{|c|c|c|c|c|}
\hline \multirow{2}{*}{\multicolumn{2}{|c|}{ Position and temperature }} & \multicolumn{3}{|c|}{ Radial displacement of system temperature difference } \\
\hline & & $20^{\circ} \mathrm{C}$ & $30^{\circ} \mathrm{C}$ & $40^{\circ} \mathrm{C}$ \\
\hline \multirow{4}{*}{ Pier 7\# } & Bottom of main beam & -0.54 & -0.84 & -1.12 \\
\hline & Pier top & -0.37 & -0.61 & -0.82 \\
\hline & Relative displacement & -0.17 & -0.23 & -0.3 \\
\hline & $\mathrm{L} 1 / 2$ & -0.31 & 0.52 & -0.61 \\
\hline \multirow{3}{*}{ Pier 8\# } & Bottom of main beam & -0.22 & -0.34 & -0.45 \\
\hline & Pier top & -0.22 & -0.34 & -0.45 \\
\hline & Relative displacement & 0 & 0 & 0 \\
\hline \multirow{4}{*}{ Pier 9\# } & $\mathrm{L} 1 / 2$ & -0.42 & 0.34 & -0.75 \\
\hline & Bottom of main beam & -0.38 & -0.54 & -0.72 \\
\hline & Pier top & -0.25 & -0.31 & -0.42 \\
\hline & Relative displacement & -0.13 & -0.23 & -0.3 \\
\hline \multirow{4}{*}{ Pier 10\# } & $\mathrm{L} 1 / 2$ & -0.4 & 0.45 & -0.75 \\
\hline & Bottom of main beam & -0.46 & -0.67 & -0.91 \\
\hline & Pier top & -0.31 & -0.44 & -0.58 \\
\hline & Relative displacement & -0.15 & -0.23 & -0.33 \\
\hline
\end{tabular}

It can be seen from Figure 6 to Figure 7 and Table 3 that under the effect of system temperature difference, the curved beam bridge as a whole move outward. With the increase of temperature difference, the radial displacement and tangential displacement increase, and the maximum value of radial displacement increases from $0.54 \mathrm{~mm}$ to $1.12 \mathrm{~mm}$. Due to the large longitudinal slope of the curved beam bridge, the tangential slip of the beam is serious under the action of system temperature difference, and the maximum tangential displacement increases from $12.88 \mathrm{~mm}$ to $26.6 \mathrm{~mm}$. In addition, the vertical deflection of the inner and outer sides also increases, but the difference between the inner and outer deflections is almost the same. That is to say, the internal torsion of curved beam bridge is not affected by the system temperature difference. Compared with other loads, the radial displacement of main beam relative to pier top is larger under the action of system temperature difference. Through the above analysis, it can be seen that under the action of temperature gradient, the curved beam bridge will produce large radial displacement. And the bearing will produce large lateral reaction force and vertical negative reaction force, which will easily lead to shear failure and tensile fracture failure of the bearing. Under the effect of system temperature difference, the curved beam bridge has the greatest adverse effect, which easily leads to shear failure and tensile state of the bearing and produces large radial offset and tangential slip. However, these analyses are based on the linear elastic instantaneous loading. Due to unloading, the displacement and reaction force will inevitably recover, which cannot accurately explain the mechanical mechanism of the lateral displacement. 


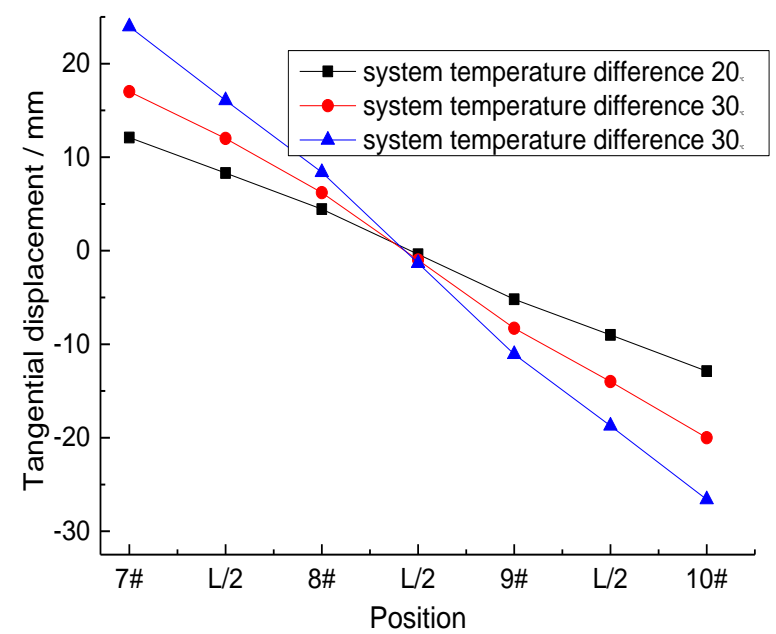

Fig. 6 - Tangential displacement under the action of system temperature difference $(\mathrm{mm})$

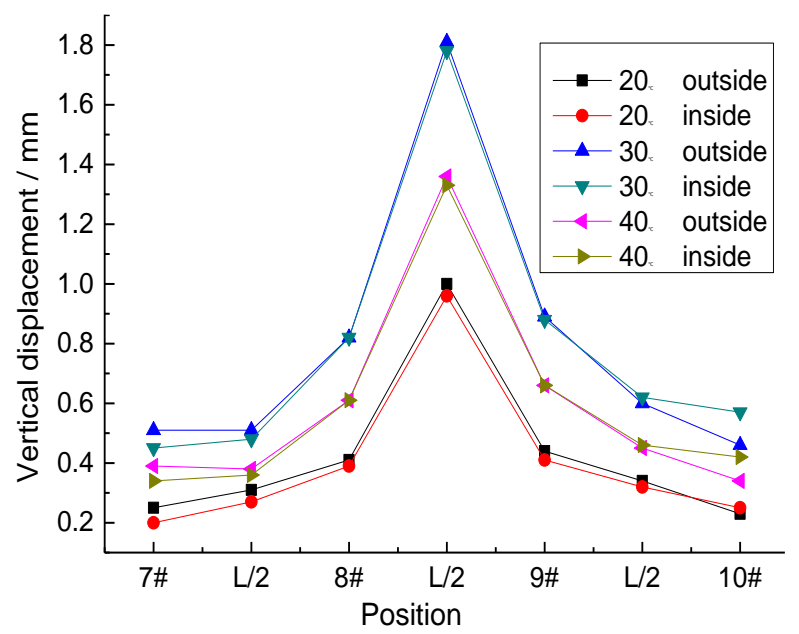

Fig. 7 - Vertical displacement under the action of system temperature difference $(\mathrm{mm})$

\section{Lateral displacement analysis considering long term cumulative effect}

Due to the friction resistance of the bearing and the bottom of the beam, the effect of gravity and other factors, the lateral offset of curved beam bridge cannot be fully recovered after the external force disappears. The residual lateral displacement exists in every external force action, and the lateral displacement is accumulated continuously under the cyclic action of external load. Therefore, the dust and garbage blocking the bearing gap, bearing material aging and bearing friction resistance are the main factors causing the lateral displacement of curved beam bridge cannot be restored. Among them, dust and garbage blocking the gap of the bearing is closely related to the bearing management and maintenance, and the bearing material aging is related to the bearing material properties and the environmental conditions, which is not easy to quantitative analysis. This paper attempts to use the Combined39 element of ANSYS software to build the bearing. The element can simulate the nonconservative system and the hysteretic effect of loading and unloading, so it can approximately simulate the cumulative displacement effect of rubber bearing which cannot be restored by friction and slip under various actions. It can also be used to calculate the residual displacement accumulation process under repeated loading.

For space limitation, taking the curved beam under the action of system temperature rise of $40^{\circ} \mathrm{C}$ as an example. Figure 8 shows the residual displacement of the curved beam after repeated action of the overall temperature rise and fall for 7 times. It can be seen that the maximum 
cumulative residual displacement is $3.65 \mathrm{~mm}$. Compared with Table 3 , the elastic radial displacement under the action of once a load is $1.12 \mathrm{~mm}$, which indicates that with the repeated action of temperature effect, the residual displacement gradually accumulates, and is greater than the radial displacement of the structure under the once a load. Figure 9 shows the cumulative process of the residual displacement of the bearing with the maximum displacement and the loading and unloading of the system temperature. It can be seen from Figure 9 that the residual displacement accumulation process of the bearing with the maximum displacement. With the cycle of temperature loading and unloading, the increment of residual displacement decreases gradually, which is basically consistent with the engineering practice. That is to say, with the aging of bearing material and the increase of friction, especially the blockage of dust and garbage, the increment of residual displacement gradually decreases.

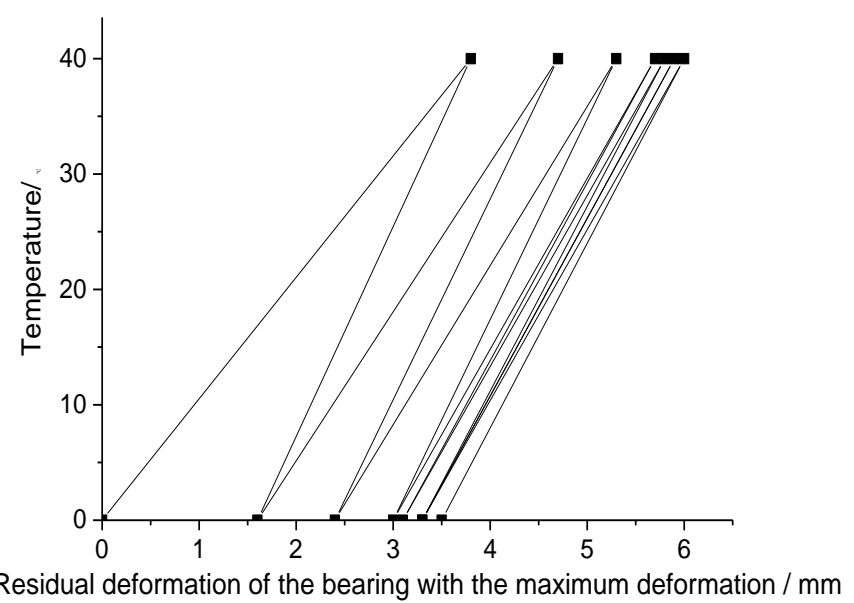

Fig.8 - Cumulative time-history of residual displacement of the largest displacement

The deviation analysis considering long-term cumulative effect can quantitatively explain the lateral displacement mechanism of curved beam bridge, which is highly consistent with the actual bridge operation. In summary, the lateral deviation of the curved beam bridge is the overall disease response caused by the radial displacement accumulated under the action of the external load combination dominated by temperature load.

\section{REINFORCEMENT AND RENOVATION MEASURES FOR CURVED BEAM BRIDGE WITH LATERAL DEVIATION}

The treatment measures of damaged bridges should be based on the actual situation, fully consider the interference and influence of traffic, and should have strong operability. The construction technology, equipment and equipment selected for reinforcement should be closely combined with the actual conditions of the construction site and have good reliability. According to the disease characteristics of the curved beam bridge, the treatment measures adopted by the bridge are firstly vertical jacking and lateral pushing to achieve the beam reset, and at the same time replace the damaged bearing. Then the pier is reinforced. Through the methods of component reinforcement, accessory component improvement and structural performance improvement, the existing diseases can be eliminated, the original function of the bridge can be restored, and the service life of the bridge can be effectively extended. 


\section{Restoration of beam}

A vertical jack is installed between the beam bottom and the capping beam for vertical lifting. After jacking up, the system is converted. The control system is converted to translational system, then the horizontal translation jack is used for the reset construction.

\section{Calculation of vertical jacking force}

According to the jacking height (the jacking height of each support is $1.5 \mathrm{~cm}$ ) designed in the reinforcement and maintenance scheme, the maximum vertical bearing reaction force on each pier of curved beam under the most unfavourable condition is calculated. Based on this, the jacks are selected and configured. The vertical reaction force of each bearing is shown in Table 4 . The sum of the inner and outer vertical reaction forces of each bearing is used as the basis for setting the number of jacks.

Tab.4 - Each bearing reaction ( $k N)$

\begin{tabular}{ccc}
\hline Position & Vertical reaction forces of bearing & Sum of reaction forces \\
\hline Pier 7\# outer & 1926.91 & 3502.06 \\
Pier 7\# inner & 1575.15 & 8236.63 \\
\hline Pier 8\# outer & 4279.08 & 8266.51 \\
Pier 8\# inner & 3957.55 & \multirow{2}{*}{3469.43} \\
\hline Pier 9\# outer & 3950.55 & \\
Pier 9\# inner & 4315.86 & 1805.28 \\
\hline Pier 10\# outer & 1664.15 & \\
Pier 10\# inner & &
\end{tabular}

In order to ensure the smooth lifting construction of the curved beam bridge, the jacking force of jack is $1.5 \sim 2.0$ times of the maximum bearing vertical reaction force.

\section{Calculation of lateral jacking force}

The lateral jacking force must consider both the friction force and the additional lateral force caused by the dead load. The calculation formula is as follows.

$$
\mathrm{T}=\mathrm{Hf}+\mathrm{Hi}=\mu \mathrm{R}+\mathrm{Hi}
$$

Where $\mathrm{T}$ is the lateral jacking force of each bearing. Hf is the friction force at each bearing. $\mathrm{Hi}$ is the additional lateral force caused by dead load. $\mu$ is the friction coefficient of sliding block, and the value is 0.1 . $R$ is the bearing reaction. According to Equation 1, the lateral jacking force is shown in Table 5.

Tab.5 - Lateral jacking force of the pier $(\mathrm{kN})$

\begin{tabular}{ccccc}
\hline Position & Bearing reaction R & Friction force Hf & Lateral force Hi & Lateral jacking force T \\
\hline Pier 7\# & 3502.06 & 350.21 & 2.65 & 352.86 \\
Pier 8\# & 8236.63 & 823.66 & 13.02 & 836.68 \\
Pier 9\# & 8266.51 & 826.65 & 15.76 & 842.41 \\
Pier 10\# & 3469.43 & 346.93 & 17.26 & 364.19 \\
\hline
\end{tabular}

\section{Jack configuration and beam lifting}

According to the above calculation, the hydraulic jack with the jacking force of 200t is selected. The height of the jack is $150 \mathrm{~mm}$, the base diameter is $210 \mathrm{~mm}$, and the stroke of the jack is $50 \mathrm{~mm}$. The horizontal translation jack is a hydraulic jack with a jacking force of $200 \mathrm{t}$. The height of the jack is $375 \mathrm{~mm}$, the base diameter is $300 \mathrm{~mm}$, and the stroke of jack is $140 \mathrm{~mm}$. The 
vertical jack and translation jack are installed in the reaction frame, and all lifting jacks are installed in the upward direction. The axis of the jacks shall be vertical during installation. The lifting system shall be inspected before lifting. In order to observe and assess the working state of the whole jacking reset process, the jack up test was carried out before the formal lifting, with the lifting height of $5 \mathrm{~mm}$. During the trial jacking, the initial loading is $80 \%$ of the theoretical jacking force, then load slowly. Until it is determined by the displacement sensor that each point has been separated, and then lift it to $5 \mathrm{~mm}$. After 10 minutes of shutdown, check whether the supporting points and lifting supports of the bridge are deformed and whether the loading points are damaged by local pressure. After the lifting test is qualified, the formal lifting height is $15 \mathrm{~mm}$. The jacking is divided into 5 stages. The jacking height of each stage is $3 \mathrm{~mm}$, and the lifting height difference of adjacent piers is controlled within $2 \mathrm{~mm}$. When the jacking force approaches the dead load of the beam, the lifting speed shall be slowed down and the jacking shall be lift up slowly to the predetermined height.

\section{Push beam body}

After vertical lifting, polytetrafluoroethylene (PTFE) plate and stainless steel plate are used as lateral reset sliding plane. The sliding plane is set at the original support. According to the specific deviation of the main beam of each pier, the translation reaction frame and translation jack are installed. The offset of the main beam at pier 7\#, pier 8\#, pier $9 \#$ and pier $10 \#$ is $12 \mathrm{~cm}, 6.5 \mathrm{~cm}$, $2 \mathrm{~cm}$ and $0 \mathrm{~cm}$ respectively. The method of pushing the beam body and adjusting the bearing position is adopted for the transverse reset of the main beam. The transverse pushing of the beam body is carried out in order by stages and grades. The horizontal reset amount of curved beam is controlled at $1 \mathrm{~cm}$. The displacement difference of the main beam at the adjacent pier should be controlled within $1 \mathrm{~cm}$. When the displacement difference is $1 \mathrm{~cm}$, the maximum tensile and compressive stress of the top and bottom plate of the beam does not exceed the tensile and compressive strength of the concrete. The horizontal reset process of beam body is mainly controlled by pushing displacement and assisted by pushing force control. The numerical analysis shows that the maximum principal tensile stress of the top and bottom plate is $1.24 \mathrm{MPa}$ [9], which does not exceed the design tensile strength of C50 concrete, so the lateral launching construction is safe and feasible.

\section{Replace the bearing}

The lateral displacement of curved beam bridge is accompanied by shear of bolts, rupture of bearing, and failure of stripping. Therefore, the bearing should be replaced in the restoration stage of the beam body. When the bridge is jacked and pushed to predetermined height and position according to the scheme, the old bearings that have been destroyed are removed. New bearings are also replaced and installed according to the correct position. When mounting the bearing, the bottom and top should be levelled, and the upper and lower steel plates of the bearing should be glued with epoxy resin.

\section{Pier reconstruction and reinforcement and anti- lateral-deviation measures}

For the damaged pier, the reconstruction method is to widen. The pier is widened by $30 \mathrm{~cm}$ on both sides of the longitudinal direction of bridge and $20 \mathrm{~cm}$ on both sides of the transverse direction of bridge. Pier cap, lateral limit stop and vibration isolation rubber block are added. The pier cap and stop block are not set before the pier reconstruction, so the lateral limit of curved beam is insufficient. The reconstructed pier has a good limit capacity to the lateral displacement of the beam (see Figure 9). The widening of the pier body and the addition of reinforcement in the pier can strengthen the crack resistance and bearing capacity, which can effectively prevent the pier from diseases. In addition, for the crack width $d<0.15 \mathrm{~mm}$, the surface sealing treatment is 
adopted. For the crack width $\mathrm{d}>0.15 \mathrm{~mm}$, the pressure grouting method is used to reinforce the crack. Due to the influence of beam displacement and asphalt pavement milling, all expansion joints need to be replaced, and a new type of steel comb plate expansion device is used.

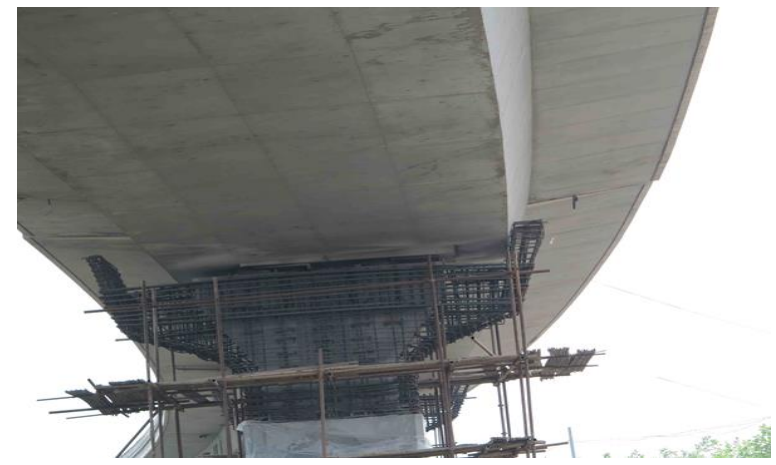

Fig. 9 - Reinforcement and reconstruction of bridge piers

\section{EVALUATION OF RECONSTRUCTION EFFECT BASED ON LONG TERM HEALTH MONITORING DATA}

As mentioned above, detailed reinforcement and transformation work has been conducted for the lateral displacement disease of curved beam bridge, but the actual effect of the measures taken needs additional measured data for verification. The long-term health monitoring system of the bridge was established, and the measured data of nearly one year (October 14, 2015, September 17, 2016) of the reinforcement and reconstruction scheme were collected. The temperature load and the corresponding lateral displacement of beam which mainly affect the disease are extracted. Data at night are extracted, and data points are extracted every 15 days to avoid the influence of vehicle load on the monitoring results. According to the selected data points, the probability statistics method is applied to screen out the points that are affected by the vehicle load and considerably change.

\section{Temperature data analysis}

The temperature load selects a meaningful time in summer and winter to analyse the temperature field monitoring data of the box girder for obtaining the variation characteristics of the beam under the overall annual temperature change. According to meteorological data, the average temperature in August is the highest in a year. Figure 10(a) presents the temperature curve of August 2016, from which the temperature data of August 11-13 with the highest temperature are selected for analysis. Notably, one data point is taken every hour. Figure 10(b) shows the temperature data curve of measuring point 5 inside the beam and measuring point 2 outside the beam (the location of points is shown in Figure 1.). Figure 10(b) shows that the time of the peak temperature inside the beam (point 5) lags approximately 6 hours behind the peak temperature outside the beam (point 2). This lag is caused by the hysteresis of the heat conduction inside the concrete. The meteorological data indicate that the temperature in February 2016 is relatively low. According to the temperature distribution curve of February shown in Figure 11(a), the temperature data of February 6-8 are selected for analysis, and one data point is taken every hour. Figure 11 (b) shows the distribution curve of internal and external temperatures of box girder in this period. The analysis of the measured temperature data reveals that the temperature variation rules in winter and summer are similar, and the figure is similar to the sinusoidal curve. The temperature of the top plate is higher than the external and bottom web temperatures in the same period due to the influence of solar radiation. The temperature difference between top and bottom plates is approximately $10^{\circ} \mathrm{C}$. Web temperature peak, which is the peak of the top plate temperature, appears later. The temperature of the web will be influenced by solar radiation and is mainly 
CIVIL

ENGINEERING

THE CIVIL ENGINEERING JOURNAL 1-2021 JOURNAL

affected by heat transfer of concrete. Heat conduction phenomenon is also evident at the bottom of the web.

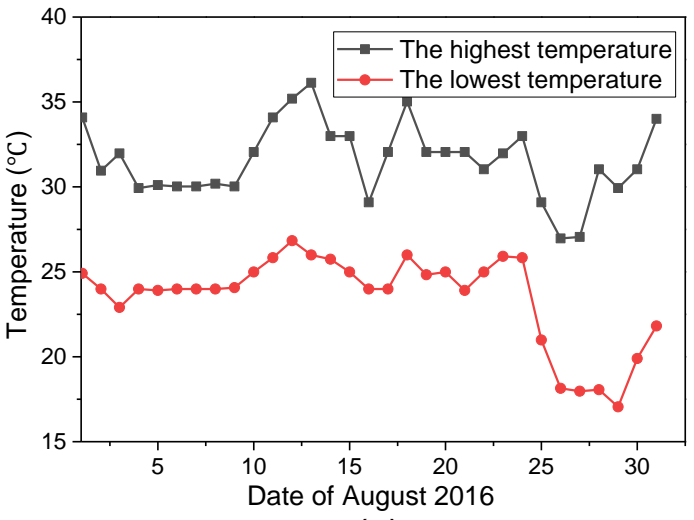

(a)

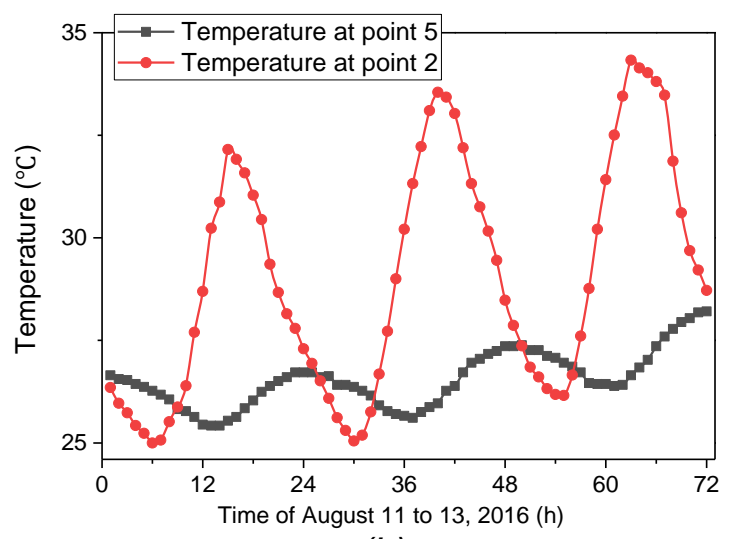

(b)

Fig. 10 - Temperature distribution curve of August 2016 and temperature history of beam

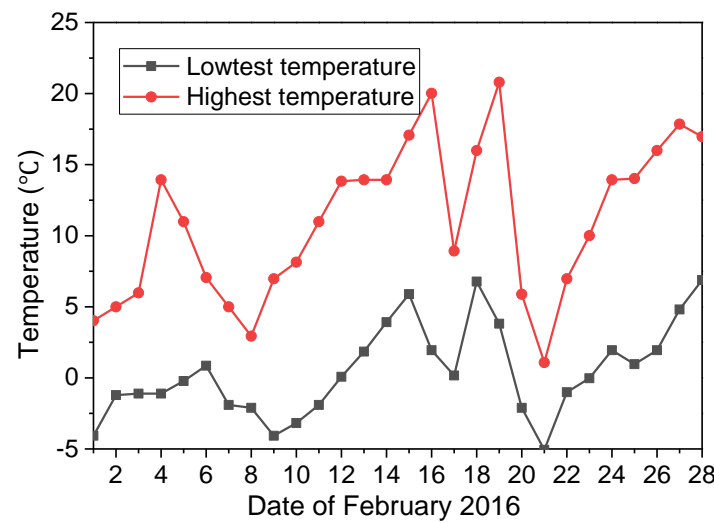

(a)

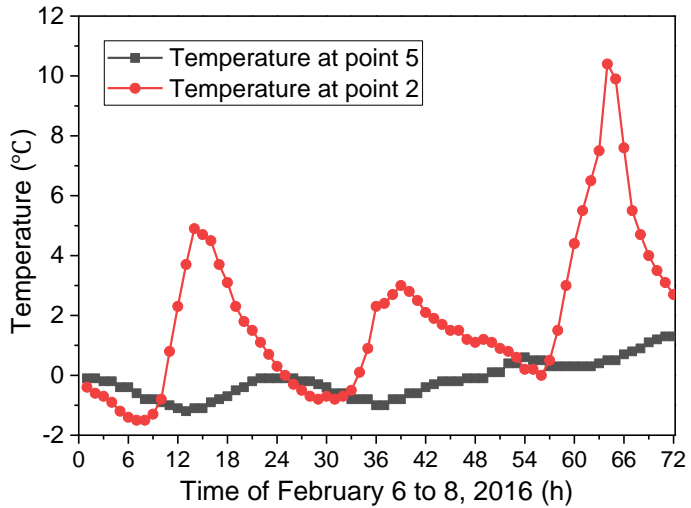

(b)

Fig. 11 - Temperature distribution curve of February 2016 and temperature history of beam

\section{Measured lateral displacement under the influence of temperature}

The lateral displacement time history curves of piers \#7 and \#36 are shown in Figure 12. The Figure 12 shows that only pier \#7 has a horizontal displacement of $5 \mathrm{~mm}$ in December 2015, while pier \#36 has slight change in the displacement of sensor. At the same time, the change trend of lateral displacement is the same as that of temperature. With the increase in temperature, the beam expands and exhibits deviation (pointing to the lateral) and up shift of $\Delta 1$. With the loss of the temperature, the deviation move of main girder will gradually restore (pointing to the inside). The amount is recovered as $\Delta 2$ due to the influence of gravity force component and the function of the friction between bearings, that is, $\Delta 1<\Delta 2$. Therefore, in the process of the cycle of heating and cooling, lateral displacement moves too late to complete the recovery of beam and gradually accumulates. Data from January 23, 2016 to June 20, 2016 are taken for analysis to intuitively study the influence of temperature on lateral displacement, and data points are taken every minute. In two days of normal traffic, the average temperatures are $7{ }^{\circ} \mathrm{C}$ and $24{ }^{\circ} \mathrm{C}$, respectively. For urban bridges, the load distribution of vehicles in two days is roughly the same. Therefore, temperature is the influencing factor of the transverse displacement amount in two days. Figure 13 shows the transverse displacement curve of pier \#36 in the two days. The transverse displacement of the main beam is low at low temperature and high at high temperature. The displacement values of the 
remaining piers also show a similar correlation with temperature. The analysis of the 1-year monitoring data indicates that the lateral displacement is mainly caused by the deviation and torsion of structure under the influence of the system temperature difference and the temperature gradients. This deduction is consistent with the finite element analysis conclusion above.

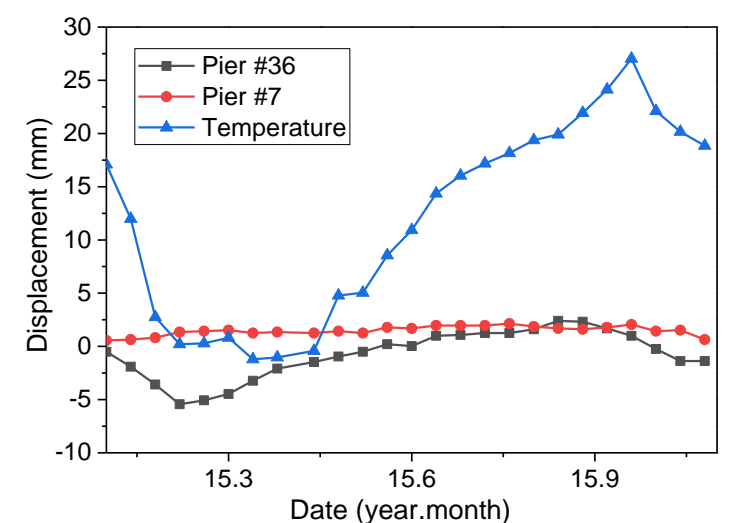

Fig. 12 - Time history curve of lateral displacement

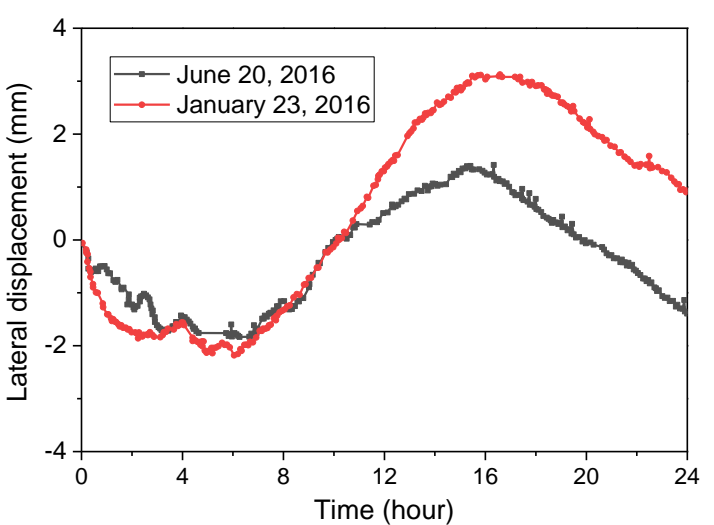

Fig. 13 - Lateral displacement of pier \#36

Linear correlation coefficient $\mathrm{R}$ is used to further analyse the correlation between displacement and temperature. The scatter of the correlation between the lateral displacement and temperature of pier \#36 is shown in Figure 14 as an example. The lateral displacement is roughly linear with the temperature. According to the linear regression method, the absolute value of the correlation coefficient between them is 0.9232 , which is greater than 0.8 . In other words, the lateral displacement is linear with temperature. The displacement of the remaining piers also shows a similar correlation with the temperature.

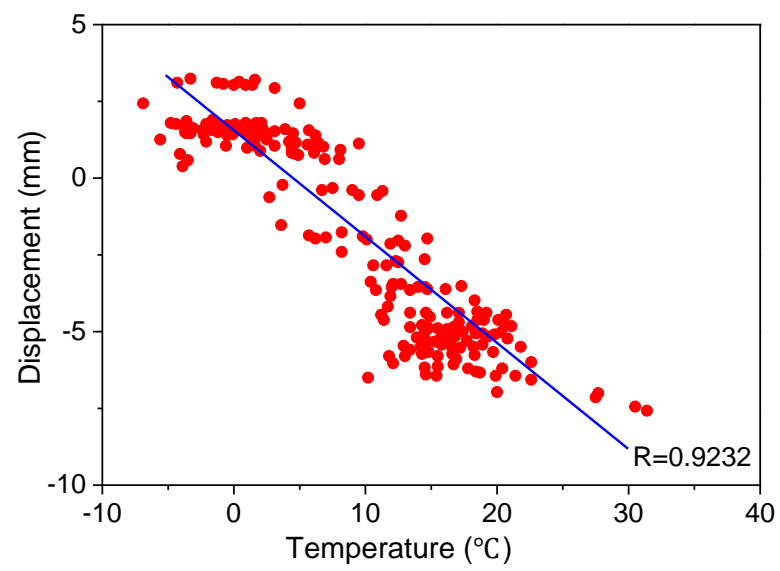

Fig. 14 - Correlation between the lateral displacement of pier \#36 and temperature

\section{Transverse creep measurement after reinforcement and transformation}

According to bearing technical data, the maximum allow lateral displacement of the bearing is $\pm 40 \mathrm{~mm}$, and the maximum allow longitudinal displacement is $\pm 100 \mathrm{~mm}$. In the past year, the maximum transverse displacement was $5.6 \mathrm{~mm}$, which was less than the maximum displacement of the support. This result indicates that the bearing does not break during the monitoring period. At the same time, the threshold of lateral displacement of the support is also set depending on the maximum displacement. In the monitoring system established above, the system will automatically alarm once the lateral deviation monitoring value exceeds the limit. 


\section{CONCLUSION}

On the basis of the detailed investigation of the lateral displacement disease, the paper analyzes the lateral displacement mechanism of the curved beam bridge under the influence of temperature. The reinforcement and reconstruction measures after the diseases of curved beam bridge are also provided. The transformation effect is analyzed and evaluated as well on the basis of the monitoring data. The main conclusions are as follows.

(1) Due to the structural characteristics of curved beam bridge, lateral displacement will occur under the influence of external load such as temperature, prestress, concrete shrinkage and creep effect, vehicle load and other factors. Therefore, to solve the problem of lateral displacement of curved beam, some preventive measures should be taken from the aspects of bridge design, construction and maintenance, so as to limit the lateral deflection and improve the service life of curved beam bridge.

(2) Numerical analysis shows that under the action of temperature gradient, the curved beam bridge produces large radial displacement, the bearing produces large transverse and vertical negative reaction forces, and the bearing is prone to shear failure and tensile fracture failure. Under the action of system temperature difference, the bearing is prone to shear failure and tension state and produces large radial offset and tangential slip. Therefore, the temperature effect is the main factor causing the lateral displacement of curved beams bridge.

(3) Without considering the long-term cumulative effect of bearing displacement, the analysis based on the assumption of one-time load instead of long-term repeated load and beam transverse displacement instead of long term cumulative displacement cannot accurately explain the mechanism of lateral displacement of curved bridge. The mechanism should be that there is residual lateral displacement in each load action under the action of internal and external factors. Under the action of repeated load, the lateral displacement is accumulated continuously, which forms the deflection of curved beam bridge.

(4) For the curved beam bridge with lateral deflection, corresponding reconstruction and reinforcement measures can be taken to restore the normal function of the structure. At the same time, the existing diseases can be eliminated by means of component reinforcement, accessory component improvement and structural performance improvement, so as to restore the original function of the bridge and extend the service life of the bridge. For the example bridge in this paper, the long-term health monitoring data show that the bridge is in good service condition after reconstruction and reinforcement, and there is no serious lateral displacement disease.

\section{ACKNOWLEDGEMENTS}

This work was supported by Key R\&D and Promotion Projects in Henan Province of China (No.192102310227).

\section{REFERENCES}

[1] Deng T., Zhang J., Bayat M., 2018. Simplified Method and Influence Factors of Vibration Characteristics of Isolated Curved beam bridge. Structural Durability \& Health Monitoring, vol. 12(3): 189-212

[2] Granata M.F., Margiotta P., Arici M., 2013. A Parametric Study of Curved Incrementally Launched

Bridges. Engineering Structures, vol. 49: 373-384

[3] Sali J., Mohan R.P., 2017. Parametric Study of Single Cell Box Girder Bridge under Different Radii of Curvature. Applied Mechanics and Materials, vol. 857: 165-170

[4] Samaan M., Kennedy J.B., Sennah K.,2007. Impact Factors for Curved Continuous Composite Multiple-box Girder Bridges. Journal of Bridge Engineering, vol. 12(1): 80-88 
[5] Sarode A.B., Vesmawala G.,2014. Parametric Study of Horizontally Curved Box Girders for Torsional Behavior and Stability. International Refereed Journal of Engineering and Science, vol. 3(2): 50-55 [6] Fatemi S., Ali M.M., Sheikh A., 2016. Load Distribution for Composite Steel-concrete Horizontally Curved Box Girder Bridge. Journal of Constructional Steel Research, vol. 116(1): 19-28

[7] Kim S., Cho K., Won J., 2009. A Study on Thermal Behaviour of Curved Steel Box Girder Bridges Considering Solar Radiation. Archives of Civil and Mechanical Engineering, vol. 9(3): 59-76

[8] Moorty S., Roeder C.W.,1992. Temperature-dependent Bridge Movements. Journal of Structural Engineering, vol. 118(4): 1090-1105

[9] Lin L.J., 2015. Study on Lateral Deviation of the Curved Beam Bridge, dissertation for the degree of master(Zhengzhou University): 13-78

[10] Li J., Feng G.J., Lin L.J. Chen H., 2017. Lateral Creep Displacement Mechanism Analysis of Curved Beam Considering the Cumulative Effect of Residual Displacement under Temperature. Science Technology and Engineering, vol. 17(34): 124-129

[11] Hossain M., Zisan M. Haque M., 2019. Analysis of Distortion-induced Stress and Retrofitting Technique of Curved Twin I-girder Composite Bridge. Arabian Journal for Science and Engineering, vol. 44(5): 4395-4404

[12] Li J., Chen H., Lin L.J., 2017. Lateral Creep Displacement Mechanism Analysis of Curved Beam Considering the Cumulative Effect of Residual Displacement under Temperature. Construction Technology, vol. 46(16): 110-113 